\title{
Our Readers Write ...
}

\section{Niels Bohr, Resonance, Vol.18, No.10, October 2013.}

I read with great interest your articles on Niels Bohr, and am indebted to you for my enlightened state of mind. If not for such articles, to know about eminent scientists through their biographies is a costly and painful exercise, as most authoritative biographies are foreign publications with a high price tag attached to them. Secondly, I have always felt that our science programmes lack the personal touch in that they do not delve into the personality much but only on their work. I can understand it from the utility point of view, but the history of technology or for that matter science can teach budding scientists about the characteristics they should possess for a successful career and also how things evolved. It can also improve their language skills.

D Balakrishnan

Email: bala572@yahoo.com

I enjoyed your October 2013 issue on Niels Bohr and his work. However, I have some comments. I presume that one of the aims of Resonance is to help develop critical thinking in the student community, which would, hopefully, produce some 'independent thinkers and scientific leaders'. For this purpose, it is desirable that even articles about the greatest scientists should adopt a sceptical attitude. I have read that Niels Bohr's overpowering personality forced dissenters like Louis de Broglie and Erwin Schrödinger (also scientists of roughly equal standing) to suppress their own ideas and follow Copenhagen in their research. Both Heisenberg and Dirac didn't think much of the complementarity principle, and Dirac's view of the uncertainty principle was similar. Einstein was of the view that Quantum Mechanics was a theory of ensembles. Dirac's views of quantum physics in 1930 and, say, 1970, were diametrically opposite (see The Physicist's Conception of Nature edited by Jagdish Mehra). In the book Foundations of Quantum Physics, Toyoki Koga exhibits a solution to the Schrödinger equation for one particle, adapting old ideas of de Broglie. This represents a localised field. He also shows how an ensemble of such solutions gives a de Broglie wave, thereby partly supporting Einstein. The above information may be of some interest to your readers.

R S Chakravarti

Reader (retired), Dept of Mathematics Cochin University of Science and Technology, Cochin 682022,Email: chakrsc@rediffmail.com

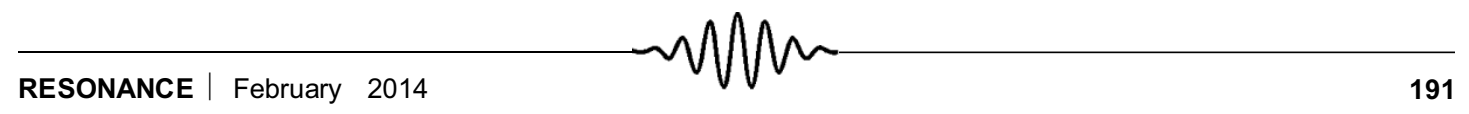

